\title{
Amlodipine-induced gingival hyperplasia in chronic renal failure: a case report
}

\author{
*Aldemir $\mathrm{NM}^{1}$, Begenik $\mathrm{H}^{2}$, Emre $\mathrm{H}^{2}$, Erdur $\mathrm{FM}^{2}$, Soyoral $\mathrm{Y}^{2}$
}

1. Department of Internal Medicine, Faculty of Medicine, Yuzuncu Yil University, Van, Turkey

2. Department of Nephrology, Faculty of Medicine, Yuzuncu Yil University, Van, Turkey

\begin{abstract}
Amlodipine is a dihydropyridine calcium channel blocker that is used in the management of both hypertension and angina. Amlodipine induced side effects are headache, dizziness, edema, flushing, palpitations, and rarely gingival hyperplasia. The exact reason of amlodipine-induced gingival hyperplasia is not known. We presented a case with chronic renal failure (CRF) that developed gingival hyperplasia due to amlodipine use, which improved after ceasing the drug.

Keywords: Amlodipine, gingival hyperplasia, chronic renal failure

African Health Sciences 2012; (4): 576 - 578 http://dx.doi.org/10.4314/ahs.v12i4.30
\end{abstract}

\section{Introduction}

Amlodipine is a long-acting calcium channel blocker belonging to dihydropyridine group, which is used for the treatment of hypertension and angina. Pharmacokinetic profile characteristic of this group, which would also have an increased oral bioavailability and extended clearance time. A single intravenous dose of $10 \mathrm{mg}$ resulted in an absolute bioavailability of $64 \%$ and a calculated elimination half-life of 34 hours $^{1}$. Side effects of amlodipine usage involve headache, dizziness, edema, flushing, palpitation and rarely gingival hyperplasia ${ }^{2}$. We presented here a case with stage- 3 chronic renal failure (CRF), which developed gingival hyperplasia due to amlodipine use.

\section{Case report}

A 39-year-old male patient, who had been under follow up because of the diagnosis of stage- 3 chronic renal failure and hypertension for one year, appealed to the dentist with the complaint of gingival hyperplasia. The patient who was planned surgery was referred to the nephrology policlinic to be given preoperative recommendations for renal failure. It was revealed that the patient admitted to our policlinic had used amlodipine $10 \mathrm{mg} 1 \times 1$ and carvedilol $6,25 \mathrm{mg} 2 \times 1$ for approximately 1 year and that the patient's complaint of gingival

\footnotetext{
*Corresponding author:

Mehmet Naci Aldemir

Sanlýurfa Education and Research Hospital, Internal Medicine Department

Sanlýurfa, Turkey

Tel: +90 4143186000

E- mail: aldemirmn@gmail.com
}

hyperplasia had begun 2 months after the use of these drugs and had gradually worsened. Since the gingival hyperplasia was assumed to be due to amlodipine, the medications were ceased and the patient was prescribed angiotensin receptor blockers. During follow up, a remarkable improvement of the patient's gingival hyperplasia was observed. The patient's figures of during the use of amlodipine and 3 months after discontinuation have been showed in figures 1 and 2 .

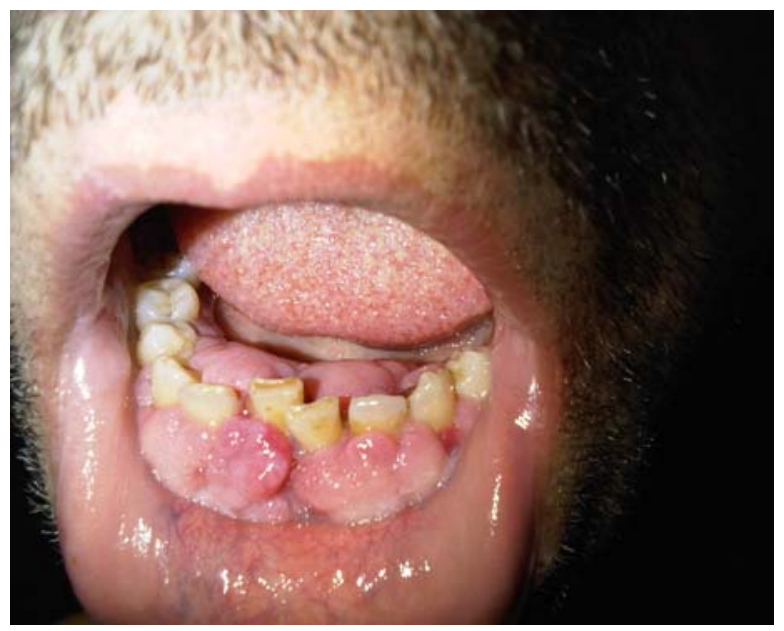

Figure 1: Amlodipine induced gingival hyperplasia 


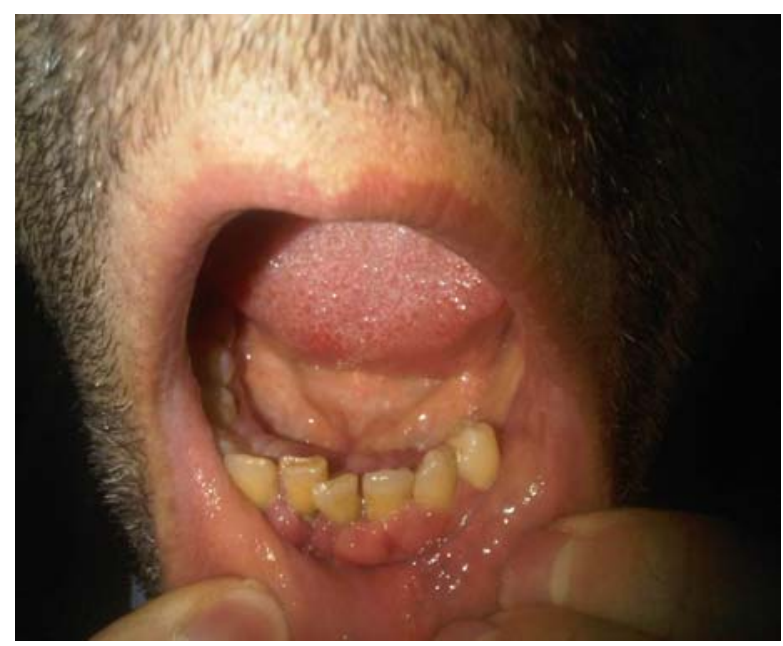

Figure 2: Regression of gingival hyperplasia during 3 months after discontinuation of amlodipine.

\section{Discussion}

The drugs causing gingival hyperplasia can be discussed as three major groups: Anticonvulsants (phenytoin), immunosuppressive agents (cyclosporine A) and calcium channel blockers ${ }^{3}$. Among calcium channel blockers, the ones causing gingival hyperplasia in order of frequency are nifedipine $(6.3 \%)^{4}$, verapamil $(4.1 \%)^{5}$ and amlodipine with lower rates $(1.3 \% \text { to } 3.3 \%)^{3,4,6}$.

Amlodipine is a long-acting calcium channel blocker agent from dihydropyridine group, which is used for the treatment of hypertension and angina. The side effects developed due to the use of amlodipine are headache, dizziness, edema, flushing, palpitation, and rarely gingival hyperplasia ${ }^{2}$.

Amlodipine-associated gingival hyperplasia was first reported in $1993^{2}$. The majority of the cases in the literature were published in the journals of dentistry. Gingival hyperplasia arises approximately 2 to 3 months after the use of amlodipine ${ }^{7}$. In our patient, it began to occur after 2 months, the patient continued to take the drug since the patient did not know that it might be related to the drug and the patient appealed to the dentist at first.

In the literature, there are three prevalence studies along with case reports regarding amlodipineinduced gingival hyperplasia. Gingival hyperplasia due to the use of amlodipine was found in $5(3.3 \%)$ of 150 patients in the study performed by Jorgensen et al. in $1997^{3}$, in $3(1.7 \%)$ of 181 patients in the study conducted by Ellis et al. in $1999^{4}$, and in $4(1.3 \%)$ of 301 patients in the study performed by Ono et al. in $2010^{6}$. To our knowledge, our reported case is the first case with CRF in the literature to develop hyperplasia due to amlodipine.

Although the exact reason of drug-induced gingival hyperplasia is not known, some well-known risk factors are gingival inflammation resulted from poor oral hygiene, presence of dental plaques, the dose and duration of the drug used ${ }^{8,9}$. The underlying mechanism remains to be fully understood. However, two main inflammatory and noninflammatory pathways have already been suggested. The proposed non-inflammatory mechanisms include defective collagenase activity due to decreased uptake of folic acid, blockage of aldosterone synthesis in adrenal cortex and consequent feedback increase in ACTH level, and upregulation of keratinocyte growth factor (KGF). Alternatively, inflammation may develop as a result of direct toxic effects of concentrated drug in crevicular gingival fluid (CGF) and/or bacterial plaques. This inflammation could lead to the upregulation of several cytokine factors such as TGF$B 1^{10}$. Consequent gingival hyperplasia causes not only esthetic problems but also difficulty speaking and mastication, impairs oral hygiene and leads to malnutrition, 8,9 "Our patient did not have the habit of regular tooth brushing (only once a week) and gingival hyperplasia evolved resulted in nutritional and speaking problems". Another factor having an impact on the development of gingival hyperplasia is gender. It occurs three times more often in men than in women ${ }^{11}$. Our patient was a man with chronic renal failure. It is not known whether chronic renal failure is associated with adverse effects of amlodipine.

The primary treatment of drug-induced gingival hyperplasia involves ceasing the drug, prescribing another drug from a different group instead, and a good oral care. In case of establishing these things, gingival hyperplasia often improves. Usually, surgical approach is not needed. In the situations requiring surgery, gingivectomy or periodontal flap is performed ${ }^{12}$. Gingival hyperplasia normally begins at the interdental papillae and is frequently found in the anterior segment of the labial surfaces $^{13}$. A gingival specimen was obtained for histological examination, of which the findings were the epithelium with irregular elongation and fusion of rete ridges and bundles of collagen fibers in the subepithelial connective tissue ${ }^{6}$. However, a biopsy has not been made may be deficiency of for our case report. 
Our patient appealed to his dentist and was referred to our policlinic for preoperative evaluation because of coexisting CRF. His medication was ceased since the development of gingival hyperplasia was assumed to be associated with amlodipine and it regressed within 3 months without surgical intervention. Therefore, it is of importance that the dentists should consider the drugs in the etiology of these disorders because most of these patients appeal to the dentists.

\section{Conclusion}

When prescribing amlodipine, it should be considered that amlodipine potentially causes gingival hyperplasia. The patients should be recommended pay attention to oral hygiene and appeal to a healthcare center in case gingival hyperplasia develops.

\section{References}

1. Abernethy DR. The pharmacokinetic profile of amlodipine. Am Heart J. 1989 Nov; 118(5 Pt 2): 1100-1103.

2. Ellis JS, Seymour RA, Thomason JM, Monkman SC, Idle JR: Gingival sequestration of amlodipine induced gingival overgrowth. Lancet 1993; 341: 1102-1103.

3. Jorgensen MG: Prevalence of amlodipine related gingival hyperplasia. J Periodontol 1997; 68: 678

4. Ellis JS, Seymour RA, Steele JG, Robertson P, Butler TJ, Thomason JM: Prevalence of gingival over-growth induced by calcium channel blockers: a community-based study. J Periodontol 1997; 0: 63-67.

5. Miller CS, Damm DD. Incidence of verapamilinduced gingival hyperplasia in a dental population. J Periodontol. 1992 May; 63(5): 453456.

6. Ono M, Tanaka S, Takeuchi R, Matsumoto H, Okada H, Yamamoto H, Makiyama Y, Hirayama T, Sakamaki T, Fujii A, Akimoto Y: Prevelance of amlodipine-induced gingival overgrowth. Int J Oral-Med Sci 2010; 9(2): 96100.

7. Meraw SJ, Sheridan PJ: Medically induced gingival hyperplasia. Mayo Clin Proc 1998; 73: 1196-1199

8. Matharu MS, Van Vilet JA, Ferrari MD, Goadsby PJ. Verapamil induced gingival enlargement in cluster headache. J Neural Neurosurg Psychiatry 2005; 76: 124-127.

9. Gregoriou A, Schneider P: Phenobarbitalinduced gingival overgrowth? Report of two cases and complications in management. ASDC J Dent Child 1996; 63: 408-413.

10. Lafzi A, Farahani RMZ, Shoja MM: Amlodipine-induced gingival hyperplasia. Med Oral Patol Oral Cir Bucal 2006; 11: 480-482

11. Tavassoli S, Yamalik N, Caglayan F, Caglayan G, Eratalay K: The clinical effects of nifedipine on periodontal status. J Periodontol 1998; 69: 108112.

12. Camargo PM, Melnick PR, Pirih FQ, Lagos R, Takei HH. Treatment of drug-induced gingival enlargement: aesthetic and functional considerations. Periodontology 2000; 27: 131-138

13. Hallmon WW, Rossmann JA: The role of drugs in the pathogenesis of gingival overgrowth. A collevtive review of current concepts. Periodontol 2000; 21: 176-196. 